\title{
The Relationship between Post-colonoscopy Colorectal Cancer and Quality Indicators of Colonoscopy: The Latest Single-center Cohort Study with a Review of the Literature
}

\author{
Hayato Yamaguchi ${ }^{1-3}$, Masakatsu Fukuzawa ${ }^{2}$, Hirohito Minami ${ }^{2}$, Tadashi Ichimiya ${ }^{2}$, \\ Hiroshi Takahashi ${ }^{2}$, Yubu Matsue ${ }^{1}$, Mitsuyoshi Honjo ${ }^{2}$, Yasutake Hirayama ${ }^{1}$, \\ Daisuke Nutahara ${ }^{1}$, Junichi Taira ${ }^{1}$, Hironori Nakamura ${ }^{1}$, Takashi Kawai ${ }^{3}$ and Takao Itoi ${ }^{2}$
}

\begin{abstract}
:
Objective This study aims to elucidate the association between the clinical characteristics of postcolonoscopy colorectal cancer (PCCRC) and quality indicators (QIs) of colonoscopy.

Methods Patients with PCCRC who underwent total colonoscopy (TCS) and were histologically diagnosed with adenocarcinoma within six months to five years of the last examination were included in this study. PCCRC and normally detected cancer (NDC) identified within the same period were compared in terms of their clinicopathological characteristics. Furthermore, the QIs at PCCRC detection were compared to those at the last examination.

Results Patients with PCCRC had a significantly higher rate of colon surgery history than those with NDC (PCCRC: $25 / 76,32.9 \%$; NDC: $31 / 1,437,2.2 \%$; $<<0.001$ ), but the invasion depth in these patients was significantly shallower (PCCRC: $\leq$ Tis/ $>$ T1, 37/39; NDC: $\leq$ Tis/ $>\mathrm{T} 1,416 / 1,021 ; \mathrm{p}<0.001$ ). Among patients with PCCRC, the T1b group had significantly more non-polypoid growth (NPG)-type cases than PG-type CRC cases $(\mathrm{p}=0.018)$. The adenoma detection rate (ADR) of colonoscopists performing TCS was $30.2-52.8 \%$. Furthermore, the ADR of colonoscopists at the time of PCCRC detection $(36.7 \% \pm 5.9 \%)$ was significantly higher than that of colonoscopists who performed the last examination $(34.9 \% \pm 4.4 \% ; \mathrm{p}=0.034)$. The withdrawal time for negative colonoscopy (WT-NC) at detection was significantly longer than that at the last examination (at detection: $494.3 \pm 253.8 \mathrm{~s}$; at last examination: $579.5 \pm 243.6 \mathrm{~s}$; $\mathrm{p}=0.010$ ).

Conclusion Given that these PCCRC cases were post-colon surgery cases, had a long WT-NC, and were detected by colonoscopists with a high ADR, most cases showed lesions that were missed during the previous colonoscopy. Caution should be practiced in order to avoid missing flat, NPG-type tumors.
\end{abstract}

Key words: post-colonoscopy colorectal cancer, interval cancer, quality indicator, polypoid growth, adenoma detection rate

(Intern Med 59: 1481-1488, 2020)

(DOI: 10.2169/internalmedicine.4212-19)

\section{Introduction}

The morbidity and mortality of colorectal cancer (CRC) has been increasing (1). Regular screening using colonoscopy is considered important $(2,3)$. In addition, there is much debate concerning interval cancers, i.e. those diagnosed between examination (4-6). The Colorectal Cancer Screening Committee of the World Endoscopy Organization has defined interval CRC as that diagnosed after a screening or surveillance examination in which no cancer was detected but before the date of the next recommended examina-

${ }^{1}$ Department of Gastroenterology and Hepatology, Tokyo Medical University Hachioji Medical Center, Japan, ${ }^{2}$ Department of Gastroenterology and Hepatology, Tokyo Medical University, Japan and ${ }^{3}$ Endoscopy Center, Tokyo Medical University Hospital, Japan

Received for publication November 19, 2019; Accepted for publication January 20, 2020

Correspondence to Dr. Masakatsu Fukuzawa, masakatu8055@yahoo.co.jp 


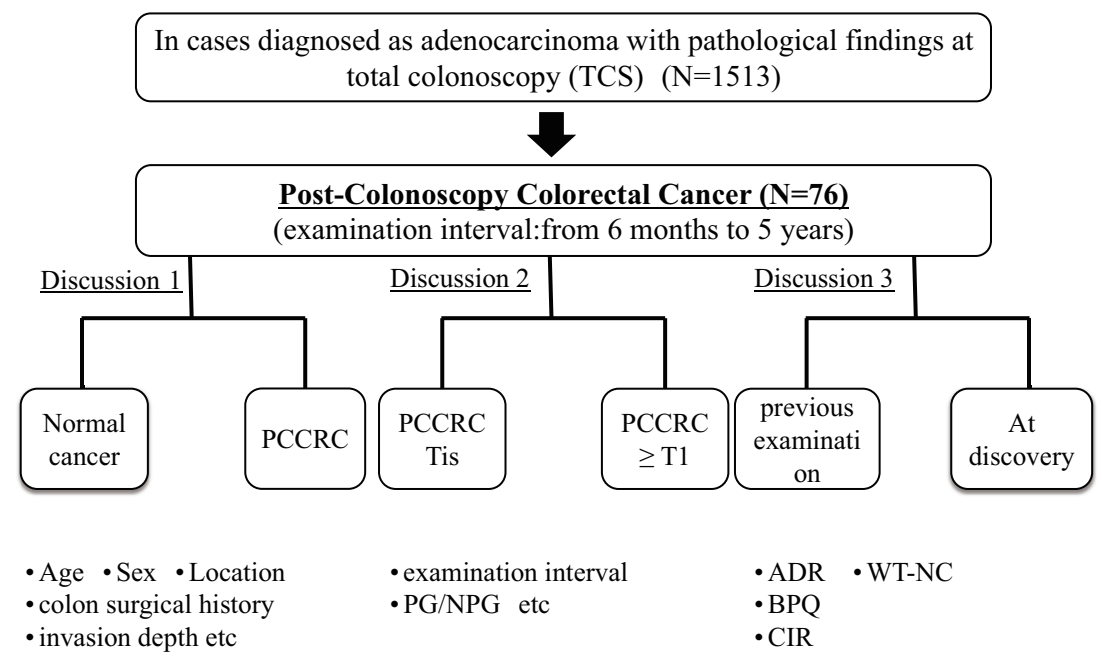

Figure 1. Flow diagram for the study.

tion (7).

The new term post-colonoscopy CRC (PCCRC), which specifically refers to CRC detected after a negative colonoscopy, was recently coined. This term seems more appropriate than "interval cancer" and can be applied to all surveillance colonoscopies in addition to screening and surveillance lesions (8). Sanduleanu et al. defined PCCRC as CRC diagnosed within five years after an index colonoscopy. The period between the last examination and the PCCRC diagnosis varies among previous reports, ranging from within 3 years to within 10 years $(3,5,7,8)$.

Eradication of PCCRC is an important goal that would lead to decreased CRC-associated mortality. The main issues that need to be clarified include the lack of standardization in testing intervals and test accuracy and inconsistency in the evaluated speed of tumor growth.

In the present study, we explored the associations between the clinical characteristics of PCCRC and quality indicators (QIs).

\section{Materials and Methods}

This study included patients with PCCRC, i.e., those who underwent total colonoscopy (TCS) between October 2008 and August 2017 at our hospital and were histologically diagnosed with adenocarcinoma within six months to five years of the last examination. Three cases of familial polyposis- and hereditary nonpolyposis-type CRC were excluded. Patients in whom colonoscopy could not be completed due to advanced stenotic CRC at the last colonoscopy and those in whom PCCRC was detected from the deep colon that could not be observed postoperatively were also excluded (Fig. 1).

CRC cases were divided into two groups based on the depth of invasion: group A, Tis stage or shallower $(\leq \mathrm{M})$; and group B, T1 stage or deeper ( $\geq \mathrm{SM})$.

The following lesion parameters were compared between the groups: patient age and sex, location of the tumor (right colon: cecum, ascending colon, and transverse colon; left colon: descending and sigmoid colon and rectum), invasion depth, macroscopic morphology, history of colon surgery, number of polyps at the last examination, examination interval, and adenoma detection rate (ADR) of the colonoscopist.

The submucosal invasion depth was measured using a microscope with an ocular lens scale. In specimens where the muscularis mucosa was incompletely disrupted by ulceration or tumor invasion, the muscularis mucosa level was estimated by drawing a line connecting the remaining parts of the muscularis. When the muscularis mucosa was completely disrupted due to tumor invasion, we measured the distance from the tumor surface to the invasive front $(9,10)$. The growth type of colorectal carcinoma was histologically divided into two types: polypoid growth (PG)-type tumors originating from the intramucosal proliferation of adenoma or carcinoma, and non-polypoid growth (NPG)-type tumors without intramucosal protuberant growth (11).

The parameters for the QI evaluation included the ADR, cecal intubation rate (CIR), bowel preparation quality (BPQ), and withdrawal time in negative colonoscopy (WTNC). In our hospital, the endoscopy nurse recorded the times for insertion into the cecum and withdrawal. In this study, we calculated the ADR as follows: the number of colonoscopies at which one or more histologically confirmed adenomas were found divided by the total number of colonoscopies performed in the same time period. We evaluated the ADR of the 26 endoscopists in our hospital. As criteria, endoscopists who had performed at least 200 colonoscopies were selected for inclusion. Furthermore, those who performed colonoscopies had to have completed at least 100 total colonoscopic examinations during the study period. WT-NC in this investigation did not include the time taken for procedures such as staining, biopsies, or polyp resection. The Boston Bowel Preparation Scale (BBPS) was used because it is extremely effective for assessing the BPQ. The total BBPS score corresponds to the sum of the segment scores for the right, transverse, and left colons, each as- 
Table 1. Clinical Characteristics of Patients and Lesions.

\begin{tabular}{lc}
\hline $\mathrm{n}$ & 1,513 \\
Mean age & $70.94 \pm 10.45$ \\
Sex $(\mathrm{M} / \mathrm{F})$ & $979 / 534(64.7 \% / 35.3 \%)$ \\
Tumor location (C/A/T/D/S/R) & $100 / 236 / 153 / 61 / 534 / 429(6.7 \% / 15.6 \% / 10.1 \% / 4.0 \% / 35.3 \% / 28.4 \%)$ \\
Surgical history of colon surgery (Yes/No) & $56 / 1,457(3.7 \% / 96.3 \%)$ \\
Depth of invasion (M/SM slight/SM massive/Deeper than MP) & $453 / 59 / 156 / 845(29.9 \% / 3.9 \% / 10.3 \% / 55.9 \%)$ \\
Normal cancer/PCCRC & $1,437 / 76(95.0 \% / 5.0 \%)$ \\
\hline
\end{tabular}

Depth of invasion: M, mucosal cancer; SM slight, tumor infiltration into the submucosal layer $<1,000 \mu \mathrm{m}$ from the muscularis mucosae; SM massive, tumor infiltration into the submucosal layer $>1,000 \mu \mathrm{m}$ from the muscularis mucosae; MP, muscularis propria.

PCCRC: post-colonoscopy colorectal cancer

Table 2. Comparison between Post-colonoscopy colorectal Cancers and Normal Cancers.

\begin{tabular}{lccc}
\hline & PCCRC & Normal cancer & p value \\
\hline $\mathrm{n}$ & 76 & 1,437 & \\
Mean age & $73.21 \pm 7.92$ & $70.82 \pm 10.56$ & 0.014 \\
Sex (M/F) & $55 / 21(72.4 \% / 27.6 \%)$ & $924 / 513(64.3 \% / 35.7 \%)$ & 0.151 \\
Tumor location (L/R) & $47 / 29(61.8 \% / 38.2 \%)$ & $977 / 460(68.0 \% / 32.0 \%)$ & 0.264 \\
Surgical history of colon surgery (Yes/No) & $25 / 51(32.9 \% / 67.1 \%)$ & $31 / 1,406(2.2 \% / 97.8 \%)$ & $<0.001$ \\
Depth of invasion (sTis/ $\geq \mathrm{T} 1)$ & $37 / 39(48.7 \% / 51.3 \%)$ & $416 / 1,021(28.9 \% / 71.1 \%)$ & $<0.001$ \\
Histological type & & & \\
tub1 & $51(67.1 \%)$ & $809(56.3 \%)$ & 0.064 \\
tub2 & $20(26.3 \%)$ & $507(35.3 \%)$ & 0.110 \\
pap & $1(1.3 \%)$ & $42(2.9 \%)$ & 0.353 \\
por & $3(3.9 \%)$ & $38(2.6 \%)$ & 0.478 \\
sig & $0(0.0 \%)$ & $3(0.2 \%)$ & 0.857 \\
muc & $1(1.3 \%)$ & $27(1.9 \%)$ & 0.585 \\
nec & $0(0.0 \%)$ & $1(0.1 \%)$ & 0.950 \\
\hline
\end{tabular}

Tumor location: L, left colon (descending colon and sigmoid colon, and rectum); R, right colon (cecum, ascending colon, and Transverse colon).

Histological type: tub1, Well differentiated type (Tubular adenocarcinoma); tub2, Moderately differentiated type (Tubular adenocarcinoma); pap, Papillary adenocarcinoma; por, Poorly differentiated adenocarcinoma; sig, Signet ring cell carcinoma; muc, Mucinous adenocarcinoma; nec, Neuroendocrine carcinoma.

PCCRC: post-colonoscopy colorectal cancer

sessed on a scale of $0-3$; the total BBPS score can therefore range from 0 to 9 (12).

The SPSS software program (version 24, SPSS, Chicago, USA) was used for the statistical analyses. Quantitative data were compared using the Mann-Whitney U test. For categorical variables, Fisher's exact test or the chi-square test was used. $\mathrm{P}$ values of $<0.05$ were considered statistically significant.

This study was approved by the Independent Ethics Committee of the Tokyo Medical University Hachioji Medical Center.

\section{Results}

There were 76 cases of PCCRC (5.02\%) among the 1,513 cases of CRC identified using TCS at our hospital (Table 1). The mean age of patients with PCCRC was 73.2 \pm 7.9 years old, and 55 were men and 21 women. CRC was located on the right side in 29 patients and on the left side in 47 . The mean examination interval was $792.3 \pm 454.8$ days. Patients with PCCRC had a significantly higher rate of history of colon surgery than those with NDC (PCCRC: 25/76; NDC: 31/1,437; $<<0.001$ ), but the invasion depth in patients with PCCRC was significantly shallower (PCCRC: $\leq$ Tis $/ \geq \mathrm{T} 1=37 /$ 39; NDC: $\leq$ Tis $/ \geq \mathrm{T} 1=416 / 1,021 ; \mathrm{p}<0.001)$. Patients with PCCRC were significantly older at the onset than those with NC (PCCRC: $73.21 \pm 7.92$ years; NDC: $70.82 \pm 10.56$ years; $p$ $=0.014)$, but there were no significant differences in the CRC location, male/female ratio, or histological type (Table 2).

Among patients with PCCRC, 37 were classified as group A $(37 / 76,48.7 \%)$ and 39 as group B $(39 / 76,51.3 \%)$. There were no significant differences between groups A and B in terms of the age, sex, tumor location, history of colon surgery, examination interval, or number of polyps at the last examination. Group B had a significantly higher rate of NPG-type tumors than group A (group A: $\mathrm{PG}=25 / \mathrm{NPG}=12$; group $\mathrm{B}$ : $\mathrm{PG}=5 / \mathrm{NPG}=12 ; \mathrm{p}=0.009$; Table 3 ). In group $\mathrm{B}, 22$ cases with invasion beyond the muscularis propria (MP) were excluded because it was too difficult to determine 
Table 3. Comparison between Shallower than Tis and Deeper than T1 in Post-colonoscopy Colorectal Cancers.

\begin{tabular}{lccc}
\hline & PCCRC $(\leq$ Tis $)$ & PCCRC $(\geq \mathrm{T} 1)$ & p value \\
\hline $\mathrm{n}$ & 37 & 39 & \\
Mean age & $72.05 \pm 6.29$ & $74.31 \pm 9.16$ & 0.213 \\
Sex (M/F) & $28 / 9$ & $27 / 12$ & 0.530 \\
Tumor location (L/R) & $24 / 13$ & $23 / 16$ & 0.597 \\
History of colon surgery (Yes/No) & $10 / 27$ & $15 / 24$ & 0.289 \\
Morphology (PG/NPG) & $25 / 12$ & $5 / 12$ & 0.009 \\
Mean examination interval (day) & $810.92 \pm 466.17$ & $774.67 \pm 449.04$ & 0.731 \\
Polyp number at last colonoscopy & $3.00 \pm 3.15$ & $2.36 \pm 2.37$ & 0.317 \\
ADR & $35.71 \pm 5.58 \%$ & $37.71 \pm 6.18 \%$ & 0.142 \\
\hline
\end{tabular}

Tumor location: L, left colon (descending colon and sigmoid colon, and rectum); R, right colon (cecum, ascending colon, and Transverse colon).

Morphology: PG, polypoid growth; NPG, non-polypoid growth.

PCCRC: post-colonoscopy colorectal cancer, ADR: adenoma detection rate

Table 4. Association with Post-colonoscopy Colorectal Cancer and Quality Indicator.

\begin{tabular}{lcccc}
\hline & $\mathrm{n}$ & Previous endoscopy & Discovery time endoscopy & $\mathrm{p}$ value \\
\hline ADR & 76 & $34.92 \pm 4.35 \%$ & $36.74 \pm 5.94 \%$ & 0.034 \\
WT-NC & 62 & $494.26 \pm 253.80 \mathrm{~s}$ & $579.48 \pm 243.56 \mathrm{~s}$ & 0.010 \\
BPQ & 62 & $8.39 \pm 0.88$ & $8.54 \pm 0.87$ & 0.107 \\
CIR & 72 & $90.3 \%$ & $93.1 \%$ & 0.483 \\
\hline
\end{tabular}

ADR: adenoma detection rate, WT-NC: average withdrawal time in negative colonoscopy, BPQ: bowel preparation quality, CIR: cecal intubation rate

whether they were PG- or NPG-type.

The ADR of TCS colonoscopists at our hospital at the time of PCCRC detection was 30.2-52.8\% (38.6 $26.6 \%)$, which was significantly higher than the ADR of colonoscopists who performed the last examination (mean ADR of colonoscopists at detection: $36.7 \pm 5.9 \%$; mean ADR of colonoscopists at the last examination: $34.9 \pm 4.4 \%$; $=0.034$ ). Furthermore, the WT-NC at PCCRC detection (579.48 \pm $243.56 \mathrm{~s})$ was significantly longer than that at the last examination $(494.26 \pm 253.80 \mathrm{~s} ; \mathrm{p}=0.010)$. No significant differences were found in terms of the BPQ or CIR (Table 4).

\section{Discussion}

In this study, most PCCRC cases were due to missed lesions, as many lesions were detected subsequent to colon surgery, had a long WT-NC, and were detected by colonoscopists with a high ADR. Many PCCRC lesions had a shallow invasion depth compared to NC, and many SM invasive cancers among PCCRC (invasion beyond the MP were excluded) were of the NPG-type, suggesting that caution is needed in order to avoid missing flat, NPG-type tumors.

To reduce the number of PCCRC cases, the number of missed tumors must be reduced. Improving the quality of colonoscopy is the most important measure for preventing missed tumors, as these represent the most influential factors for PCCRC development. The American Society for Gastro- intestinal Endoscopy (ASGE) reported on QIs and defined the key elements of quality assessment of colonoscopy (13). Lee et al. identified technique, patient safety, and patient experience as the three major elements of a colonoscopy quality assessment (14). Of these, technical measures of the colonoscopy quality are closely associated with the prevention of CRC onset and mortality.

The ADR is the most important QI. Kaminski et al. reported that the risk of the onset of interval cancer for a colonoscopist with an ADR of $<20 \%$ is $>10$-fold that for a colonoscopist has an ADR of $\geq 20 \%$ (15). Corley et al. reviewed 314,872 colonoscopies performed by 136 colonoscopists with ADRs ranging from 7.4-52.5\% and found that the risk of the onset of interval cancer in the high-ADR group was 0.52 -fold that in the low-ADR group, and that each additional percentage of ADR increased the CRC onset risk by $3 \%$ and decreased the CRC mortality rate by 5\% (16). Based on this report, the ADR is considered to be strongly correlated with interval cancer and an important index for preventing CRC onset and mortality. The ASGE has set the minimum ADR for male patients at $30 \%$ and for female patients at $20 \%$ (mean, 25\%) $(13,14)$. The ADR of the 26 TCS colonoscopists at our hospital was 30.2-52.8\% (mean, $38.6 \pm 6.6 \%$ ); therefore, they all met the minimum standards set by the ASGE. However, the ADR of the colonoscopists at the time of PCCRC detection was significantly higher than that of the colonoscopists at the last examination. The 
fact that colonoscopists with a high ADR detected more PCCRC cases suggests the importance of reducing the number of small, missed lesions on routine endoscopy.

The mean WT-NC, BPQ, and CIR were also evaluated in this study as QIs. Barclay et al. reported that the ADR was significantly higher in examinations with a mean WT-NC of $\geq 6$ minutes than in those with a mean WT-NC of $<6$ min (17). Lee et al. reported that extending the withdrawal time up to 10 minutes significantly increased the ADR; however, the ADR did not improve significantly beyond 10 minutes (18). In the present study, the WT-NC at detection was significantly longer than that at the last examination, but the average WT-NC was 6-10 minutes, which is considered an adequate withdrawal time. To increase the ADR, close observation inside the colon is a more important factor than rapid insertion of the endoscope into the cecum. However, extending the withdrawal time is expected to increase patient discomfort, suggesting the importance of completing close observation within an adequate timeframe. Furthermore, BPQ can increase the examination quality, ensuring sufficient bowel preparation. Lai et al. tested the validity of the BBPS as a BPQ assessment scale and found that good insertion was achieved by 22 endoscopists, with a median score of 6 points and an interquartile range of 6-7, while scores of $<5$ points indicated an inadequately prepared colon (19). The comparison of the BBPS scores in the present study did not reveal a significant difference between PCCRC detection and the last examination (BBPS score at detection: $8.54 \pm 0.87$; at last examination: $8.39 \pm 0.88$ ); in both the cases, BBPS scores of $>8$ were maintained, showing that the colonoscopies had been performed after adequate preparation. There were also no significant differences in the CIR at detection or the last examination. Although there were no associations with CIR, there are reports of significant correlations between a low CIR and the onset of interval cancer in the right colon (20). The CIR of all colonoscopists in our hospital was over $95 \%$. Although there was no statistical difference in CIR between previous and discovery time colonoscopy, the CIR for the previous endoscopy was noticeably lower than our rate, due to procedures performed after incomplete preparation and cases in which the cecum was not reached due to inflammation, such as in cases of ischemic colitis, were also included.

The associations between PCCRC and the QIs described above are factors of test accuracy. In addition, the examination intervals and biological factors of PCCRC should be considered. In the present study, we set the period between the last examination and the PCCRC diagnosis at six months to five years, based on the definition of interval cancer established by the World Endoscopy Organization. However, this duration is quite long and lacks uniformity, thereby making generalized comparisons difficult. The probability of missed lesions is higher in cases of short-interval PCCRC than in long-interval cases (Fig. 2); the longer the examination interval, the more likely it is for cases with slow growth detected due to the adenoma-carcinoma se- quence to be observed. The National Polyp Study recommends three years as an adequate examination interval after endoscopic resection of adenomatous polyps (21). The European guidelines classify patients who have undergone colonoscopy into three risk groups based on the number, size, and histological type of adenomas and recommend fecal occult blood screening for the low-risk group and colonoscopy after three years and one year for the mid- and high-risk groups, respectively (22). The Japan Polyp Study (JPS) recommends an interval of at least three years before a follow-up examination after colonoscopic removal of newly diagnosed adenomatous polyps (23). In addition, the time when colonoscopy performed is also important. The predictive factors for PCCRC have been reported to include a positive fecal occult blood test and a post-polyp resection $(1,2)$. Local residual/recurrence is also an issue. In Tis carcinoma, when piecemeal resection is performed or the tumor margin after resection is unclear and the curability cannot be accurately evaluated, colonoscopy should be performed approximately six months after endoscopic treatment $(24,25)$. The recurrence rate was reported to be 9.1$27.5 \%$ at 24 months after piecemeal resection $(26,27)$. Debates on the best surveillance period are ongoing worldwide, and further investigations will be required for the standardization of examination periods.

Our search of the literature revealed no reports which described that PCCRC were more frequently detected after colon surgery. However, PCCRC is reportedly more likely to develop in patients with a history of abdominal surgery and polypectomy $(2,28)$. Why PCCRC is more likely to occur in those with a history of colon surgery may be because endoscopists focus on relatively large advanced CRC lesions and may therefore small, precancerous lesions.

Furthermore, the PCCRC cases in this study had a significantly shallower invasion depth than NDC, which is consistent with previous studies that reported that PCCRC tends to be detected at earlier stages than $\operatorname{NDC}(3,29,30)$. In addition, the morphology of CRC also warrants attention: morphologically, intramucosal lesions growing to a height above the normal surrounding mucosa are classified as PG-type, whereas those that are depressed or of equal height with the surrounding normal mucosa are classified as NPG-type. PGtype $\mathrm{SM}$ cancers tend to invade the submucosa $\geq 20 \mathrm{~mm}$, whereas NPG-type SM cancers tend to invade the submucosa approximately $10 \mathrm{~mm}(31,32)$. Furthermore, interval cancers with SM invasion tend to be small and of the flat NPG-type $(30,33)$. In the present study, we compared PCCRC cases based on the invasion depth and found that group B had a significantly higher rate of occurrence of NPG-type tumors than group A, suggesting that flat, NPGtype tumors should be investigated carefully, as they can be easily missed. Differentiating between PG and NPG types is also very important in terms of their rapid growth; however, there have been very few cases of fast-growing tumors that were reported in Japan. The only report on the pathological findings of PCCRC and NDC showed that mucinous carci- 


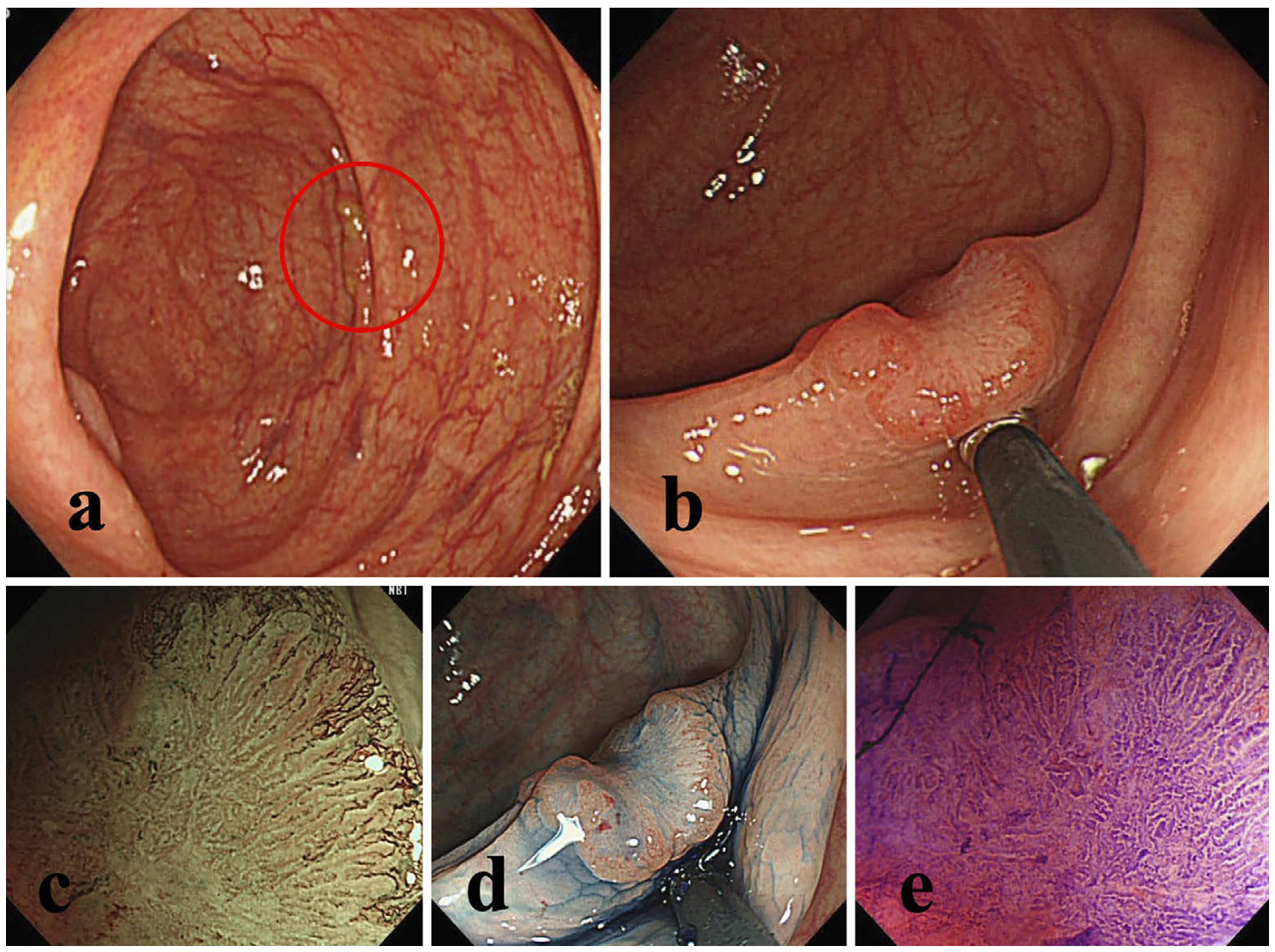

Figure 2. One example of post-colonoscopy colorectal cancer (missed lesion). a: No clear adenomatous lesions was diagnosed on TCS performed for a positive fecal occult blood test. However, the lesions was found to have been hidden behind the mucosal folds. b: 8-mm IIa+IIc lesions found in the cecum at TCS performed 11 months later for a second positive fecal occult blood test result. c-e: Magnified observation: high irregular pit pattern (Vi) and scheduled for surgery. The invasion depth was SM massive invasion. TCS: total colonoscopy

nomas were more frequent among PCCRC than among NDC (34). There were no significant histopathological differences between PCCRC and NDC in the present study. If neoplastic lesions demonstrating a high degree malignancy are also considered to be one of the reasons, then the characteristic histopathological findings should also be noted.

As of August 2019, a number of studies from multiple countries have compared the QIs between PCCRC and NDC (Table 5) (1-3, 15, 16, 20, 30, 35-42). Those studies reported the interval PCCRC rates and risk factors, and most noted that an adequate follow-up and high-quality colonoscopy were useful for preventing PCCRC, similar to the present study.

However, several limitations associated with the present study warrant mention. First, this study was a retrospective analysis that was performed at a single center. Therefore, it may be biased to some extent. CRC of various types (residual, recurrent, or fast-growing) and the pathology of PCCRC should be further investigated through large-scale randomized control trials. Second, the diagnosis of the tumor depth is sometimes controversial among pathologists. While expert pathologists diagnose tumors at our hospital, the diagnosis may still vary among pathologists. Third, we used various endoscopic scopes (CF-Q260, CF-H260, PCF-Q260AI, CFH290, PCF-H290; Olympus Medical Systems, Tokyo, Japan) for the screening and surveillance examinations. As time passes, new endoscopic scopes are introduced. Differences in the capabilities of scopes may introduce a degree of bias. However, the results of the present study can still be considered clinically significant despite these limitations.

\section{Conclusion}

This study outlined the relationship between the clinical characteristics of PCCRC and QIs. Missed lesions account for many PCCRC cases. We believe that increasing the quality of medical care and QIs will reduce the number of missed lesions and help prevent PCCRC onset. Reducing the incidence of PCCRC through high-accuracy CRC screening is a major future goal for endoscopists and key to eradicating CRC.

\section{Informed consent was obtained from all the patients.}

The authors state that they have no Conflict of Interest (COI). 
Table 5. Characteristics of Published Study for Post-colonoscopy Colorectal Cancer.

\begin{tabular}{|c|c|c|c|c|c|}
\hline Reference & Period & Country & $\begin{array}{l}\text { Definition of } \\
\text { interval CRC }\end{array}$ & PCCRC rate & Risk factor \\
\hline$(35)$ & 1991-2004 & USA & $<60$ months & 5.4 & Incomplete polypectomy, right colon,size \\
\hline$(28)$ & $1997-2002$ & Canada & 6-36 months & 3.4 & $\begin{array}{l}\text { older age, diverticular disease, proximal colon, } \\
\text { endoscopist's specialty }\end{array}$ \\
\hline (36) & 1989-2004 & USA & $<60$ months & 4.8 & proximal colon, MSI, CIMP \\
\hline$(37)$ & 2000-2005 & Spain & $<36$ months & 6.7 & $\begin{array}{l}\text { older age, male sex, the presence of another advanced } \\
\text { adenoma at first colonoscopy, history of advanced } \\
\text { neoplasia }\end{array}$ \\
\hline$(15)$ & 2000-2004 & Poland & $<60$ months & $\begin{array}{l}42 \text { interval cancer/ } \\
188,788 \text { patients }\end{array}$ & endoscopist's rate of detection of adenomas \\
\hline$(38)$ & 1992-2008 & Canada & 6-36 months & 7.9 & $\begin{array}{l}\text { colonoscopy by family physician, famale gender, } \\
\text { proximal colon, endoscopist's specialty }\end{array}$ \\
\hline$(20)$ & $2000-2005$ & Canada & 6-36 months & 9 & endoscopist's specialty, non-hospital setting \\
\hline (2) & 1994-2005 & USA & 6-36 months & 7.2 & $\begin{array}{l}\text { proximal tumor location, increased comorbidity, } \\
\text { previous diagnosis of diverticulosis, prior polypectomy, } \\
\text { endoscopist level (lower polypectomy rate, higher } \\
\text { colonoscopy volume) }\end{array}$ \\
\hline (1) & 2003-2007 & Germany & $12-100$ months & 4 & $\begin{array}{l}\text { female sex, location in the caecum or ascending colon, } \\
\text { positive faecal occult blood test, incomplete (caecum } \\
\text { not reached) }\end{array}$ \\
\hline (39) & $1976-2008$ & China & $<60$ months & $\begin{array}{l}14 \text { interval cancer/ } \\
1,794 \text { patients }\end{array}$ & incomplete resection of advanced adenomas \\
\hline (34) & 2000-2009 & Denmark & $12-60$ months & 2.6 & $\begin{array}{l}\text { female sex, localized stage at diagnosis, proximal } \\
\text { tumor location, high comorbidity burden }\end{array}$ \\
\hline$(30)$ & 2001-2010 & The Netherlands & $12-60$ months & 2.9 & $\begin{array}{l}\text { proximal colon, small size, flat lesion,inadequate } \\
\text { examination/surveillance }\end{array}$ \\
\hline (3) & $1995-2009$ & USA & 6-60 months & 6 & $\begin{array}{l}\text { proximal colon, earlier-stage cancer, lower risk of } \\
\text { death, higher rate of adenoma, family history of CRC }\end{array}$ \\
\hline (16) & $1998-2010$ & USA & $6-120$ months & 8.2 & adenoma detection rate \\
\hline$(40)$ & 2003-2009 & England & 6-60 months & 12.1 & $\begin{array}{l}\text { female sex, older age, increased comorbidity, proximal } \\
\text { colon, elective procedures, colonoscopy volume }\end{array}$ \\
\hline$(41)$ & 2001-2008 & Australia & $<60$ months & 2.8 & diverticulosis, poor bowel preparation \\
\hline$(42)$ & 2001-2012 & Denmark & $<36$ months & 9 & $\begin{array}{l}\text { colonoscopist quality (training, background, } \\
\text { certification), diverticulitis, ulcerative colitis, hereditary } \\
\text { cancer, proximal colon }\end{array}$ \\
\hline
\end{tabular}

PCCRC: post-colonoscopy colorectal cancer, CRC: colorectal cancer

\section{Acknowledgement}

We are indebted to Professor J. Patrick Barron, Chairman of the Department of International Medical Communications of Tokyo Medical University for their editorial review of the English manuscript. We are also grateful to Dr. M. Miyaoka of Tokyo Medical University Hachioji Medical Center, Japan, for his valuable editing suggestions.

\section{References}

1. Brenner H, Chang-Claude J, Seiler CM, et al. Interval cancers after negative colonoscopy: population-based case-control study. Gut 61: 1576-1582, 2012.

2. Cooper GS, Xu F, Barnholtz Sloan JS, et al. Prevalence and predictors of interval colorectal cancers in medicare beneficiaries. Cancer 118: 3044-3052, 2012.

3. Samadder NJ, Curtin K, Tuohy TM, et al. Characteristics of missed or interval colorectal cancer and patient survival: a population-based study. Gastroenterology 146: 950-960, 2014.

4. Lieberman DA, Rex DK, Winawer SJ, et al. Guidelines for colonoscopy surveillance after screening and polypectomy: a consensus update by the US Multi-Society Task Force on Colorectal Cancer. Gastroenterology 143: 844-857, 2012.

5. Singh S, Singh PP, Murad MH, et al. Prevalence, risk factors, and outcomes of interval colorectal cancers: a systematic review and meta-analysis. Am J Gastroenterol 109: 1375-1389, 2014.

6. Pabby A, Schoen RE, Weissfeld JL, et al. Analysis of colorectal cancer occurrence during surveillance colonoscopy in the dietary Polyp Prevention Trial. Gastrointest Endosc 61: 385-391, 2005.

7. Sanduleanu S, le Clercq CM, Dekker E, et al. Definition and taxonomy of interval colorectal cancers: a proposal for standardising nomenclature. Gut 64: 1257-1267, 2015.

8. Morris EJ, Rutter MD, Finan PJ, et al. Post-colonoscopy colorectal cancer (PCCRC) rates vary considerably depending on the method used to calculate them: a retrospective observational population-based study of PCCRC in the English National Health Service. Gut 64: 1248-1256, 2015.

9. Kitajima K, Fujimori T, Fujii S, et al. Correlations between lymph node metastasis and depth of submucosal invasion in submucosal invasive colorectal carcinoma: a Japanese collaborative study. J Gastroenterol 39: 534-543, 2004.

10. Tateishi Y, Nakanishi Y, Taniguchi H, et al. Pathological prognostic factors predicting lymph node metastasis in submucosal invasive (T1) colorectal carcinoma. Mod Pathol 23: 1068-1072, 2010.

11. Shimoda T, Ikegami M, Fujisaki J, et al. Early colorectal carcinoma with special reference to its development de novo. Cancer 64: 1138-1146, 1989.

12. Rostom A, Jolicoeur E. Validation of a new scale for the assess- 
ment of bowel preparation quality. Gastrointest Endosc 59: 482486, 2004.

13. Rex DK, Schoenfeld PS, Cohen J, et al. Quality indicators for colonoscopy. Am J Gastroenterol 110: 72-90, 2015.

14. Lee TJ, Rutter MD, Blanks RG, et al. Colonoscopy quality measures: experience from the NHS Bowel Cancer Screening Programme. Gut 61: 1050-1057, 2012.

15. Kaminski MF, Regula J, Kraszewska E, et al. Quality indicators for colonoscopy and the risk of interval cancer. N Engl J Med 362: 1795-1803, 2010.

16. Corley DA, Jensen CD, Marks AR, et al. Adenoma detection rate and risk of colorectal cancer and death. N Engl J Med 370: 12981306, 2014.

17. Barclay RL, Vicari JJ, Doughty AS, et al. Colonoscopic withdrawal times and adenoma detection during screening colonoscopy. N Engl J Med 355: 2533-2541, 2006.

18. Lee TJ, Blanks RG, Rees CJ, et al. Longer mean colonoscopy withdrawal time is associated with increased adenoma detection: evidence from the Bowel Cancer Screening Programme in England. Endoscopy 45: 20-26, 2013.

19. Lai EJ, Calderwood AH, Doros G, et al. The Boston Bowel Preparation Scale: a valid and reliable instrument for colonoscopyoriented research. Gastrointest Endosc 69: 620-625, 2009.

20. Baxter NN, Sutradhar R, Forbes SS, et al. Analysis of administrative data finds endoscopist quality measures associated with postcolonoscopy colorectal cancer. Gastroenterology 140: 65-72, 2011.

21. Winawer SJ, Zauber AG, O'Brien MJ, et al.; The National Polyp Study Workgroup. Randomized comparison of surveillance intervals after colonoscopic removal of newly diagnosed adenomatous polyps. N Engl J Med 328: 901-906, 1993.

22. Atkin WS, Valori R, Kuipers EJ, et al. European guidelines for quality assurance in colorectal cancer screening and diagnosis. First Edition--Colonoscopic surveillance following adenoma removal. Endoscopy 44 (Suppl): SE151-SE163, 2012.

23. Matsuda T, Fujii T, Sano Y, et al. Randomized comparison of surveillance intervals after colonoscopic removal of adenomatous polyps: Results from the Japan Polyp Study. Gastroenterology 146: S161-S162, 2014.

24. Tanaka S, Kashida H, Saito Y, et al. JGES guidelines for colorectal endoscopic submucosal dissection/endoscopic mucosal resection. Dig Endosc 27: 417-434, 2015.

25. Hassan C, Quintero E, Dumonceau JM, et al. Post-polypectomy colonoscopy surveillance: European Society of Gastrointestinal Endoscopy (ESGE) Guideline. Endoscopy 45: 842-851, 2013.

26. Yamada M, Saito Y, Takamaru H, Sasaki H, et al. Long-term clinical outcomes of endoscopic submucosal dissection for colorectal neoplasms in 423 cases: a retrospective study. Endoscopy 49: 233242, 2017.

27. Hotta K, Fujii T, Saito Y, et al. Local recurrence after endoscopic resection of colorectal tumors. Int J Colorectal Dis 24: 225-230, 2009.

28. Bressler B, Paszat LF, Chen Z, et al. Rates of new or missed col- orectal cancers after colonoscopy and their risk factors: a population-based analysis. Gastroenterology 132: 96-102, 2007.

29. Robertson DJ, Lieberman DA, Winawer SJ, et al. Colorectal cancers soon after colonoscopy: a pooled multicohort analysis. Gut 63: 949-956, 2014.

30. le Clercq CM, Bouwens MW, Rondagh EJ, et al. Postcolonoscopy colorectal cancers are preventable: a population-based study. Gut 63: 957-963, 2014.

31. Shimoda T, Ikegami M, Fujisaki J, et al. Early colorectal carcinoma with special reference to its development de novo. Cancer 64: 1138-1146, 1989.

32. Kurisu Y, Shimoda T, Ochiai A, et al. Histologic and immunohistochemical analysis of early submucosal invasive carcinoma of the colon and rectum. Pathol Int 49: 608-616, 1999.

33. Robertson DJ, Lieberman DA, Winawer SJ, et al. Colorectal cancers soon after colonoscopy: a pooled multicohort analysis. Gut 63: 949-956, 2014.

34. Erichsen R, Baron JA, Stoffel EM, et al. Characteristics and survival of interval and sporadic colorectal cancer patients: a nationwide population-based cohort study. Am J Gastroenterol 108: 1332-1340, 2013.

35. Farrar WD, Sawhney MS, Nelson DB, et al. Colorectal cancers found after a complete colonoscopy. Clin Gastroenterol Hepatol 4: 1259-1264, 2006.

36. Arain MA, Sawhney M, Sheikh S, et al. CIMP status of interval colon cancers: another piece to the puzzle. Am J Gastroenterol 105: 1189-1195, 2010.

37. Ferrández A, Navarro M, Díez M, et al. Risk factors for advanced lesions undetected at prior colonoscopy: not always poor preparation. Endoscopy 42: 1071-1076, 2010.

38. Singh H, Nugent Z, Demers AA, et al. Rate and predictors of early/missed colorectal cancers after colonoscopy in Manitoba: a population-based study. Am J Gastroenterol 105: 2588-2596, 2010.

39. Huang Y, Gong W, Su B, et al. Risk and cause of interval colorectal cancer after colonoscopic polypectomy. Digestion 86: 148-154, 2012.

40. Cheung D, Evison F, Patel P, et al. Factors associated with colorectal cancer occurrence after colonoscopy that did not diagnose colorectal cancer. Gastrointest Endosc 84: 287-295, 2016.

41. Subramaniam K, Ang PW, Neeman T, et al. Post-colonoscopy colorectal cancers identified by probabilistic and deterministic linkage: results in an Australian prospective cohort. BMJ Open 9: e026138, 2019.

42. Pedersen L, Valori R, Bernstein I, et al. Risk of post-colonoscopy colorectal cancer in Denmark: time trends and comparison with Sweden and the English National Health Service. Endoscopy 51: 733-741, 2019.

The Internal Medicine is an Open Access journal distributed under the Creative Commons Attribution-NonCommercial-NoDerivatives 4.0 International License. To view the details of this license, please visit (https://creativecommons.org/licenses/ by-nc-nd/4.0/).

\section{(C) 2020 The Japanese Society of Internal Medicine Intern Med 59: 1481-1488, 2020}

